\title{
The Influence of Feet Reflexology and Back Massage on Hemodialysis Patients' Fatigue
}

\section{Abdul Khamid* and Arifah Rakhmawati}

Nursing Department, Sekolah Tinggi Ilmu Kesehatan Abdi Nusantara, Indonesia

\section{ORCID}

Abdul Khamid: https://orcid.org/0000-0002-0423-0060

Abstract. End stage renal disease (ESRD) can lead to death and requires replacement therapy. Hemodialysis is a lifelong therapy with a frequency of 2-3 times per week for 4-5 hours per session. Prolonged dialysis can cause stress and various psychological and social problems that can lead to psychological disorders. Fatigue is also a common feeling experienced by $60-97 \%$ of patients undergoing hemodialysis. This study used a two-group pretest-posttest design with t-tests for analysing bivariate data and frequency distribution for univariate data. Measurements were taken before and after giving foot reflexology and back massages using the FAS Fatigue Assessment Scale. There were 48 patients who experienced fatigue. After being given the intervention,

Corresponding Author: Abdul Khamid; email: nanin7729@gmail.com

Published: 7 February 2022

Publishing services provided by Knowledge E

(c) Abdul Khamid and Arifah Rakhmawati. This article is distributed under the terms of the Creative Commons

Attribution License, which permits unrestricted use and redistribution provided that the original author and source are credited.

Selection and Peer-review under the responsibility of the IVCN Conference Committee.
G OPEN ACCESS there was a decrease in the value of the fatigue scale by 1.32 with a p-value $<0.01$. It can be concluded that foot reflexology and back massage have an effect on reducing feelings of fatigue in hemodialysis patients.

Keywords: end stage renal disease (ESRD), foot reflexology and back massage, fatigue

\section{Introduction}

End Stage Renal Disease (ESRD) is one of the leading causes of death in developed and developing countries where ESRD problems require replacement therapy. According to the World Health Organization (WHO), globally more than 500 million people experience ESRD that in the United States it is a major health problem with morbidity rates reaching $8,000,000$ people and as many as 600,000 people dying from the disease. Data from USRDS states that in the United States more than 65\% of patients with ESRD receive hemodialysis therapy. Worldwide, the overall prevalence of ESRD is recorded at around $10.8 \%$, affecting an estimated 119.5 million people, is quite high and is increasing rapidly [1].

The prevalence of ESRD disease ranks first in the diagnosis of the main disease in patients undergoing hemodialysis as many as 11,456 patients, $82 \%$. Indonesian data as revealed by the Indonesia Renal Registry (IRR.2015), in Indonesia only 44.2\% underwent hemodialysis therapy, namely ESRD of 18613 patients or 89\%. [2]. Currently, West Java 
province is the first province with the addition of new patients undergoing HD during 2013 as many as 4,846 people $30.03 \%$ [2].

Data on ESRDD patients at the Bekasi City Hospital based on medical records from January to December 2013 obtained 3970 patients and ESRD patients who underwent HD in December 2015 obtained 90 patients. Based on the order of the largest disease in the Bekasi City Hospital, ESRD currently ranks third after DM and TB.

The most prominent thing in patients with ESRD is fatigue, where the impact of fatigue is muscle weakness, impaired physical function, shortness of breath and depression. Fatigue symptoms have been associated with increased morbidity and mortality in ESRD patients undergoing hemodialysis. Several studies show that fatigue has a significant relationship with sleep problems, poor physical health status and depression. Fatigue is one of the problems with a fairly high prevalence among the effects of hemodialysis measures received by patients with end-stage kidney disease. Several studies have shown that $71.0 \%$ to $92.2 \%$ of patients experience fatigue and that fatigue is the most important condition to observe in patients with chronic kidney disease [3].

Prolonged dialysis process will cause stress and can cause various psychological and social problems that can cause psychological disorders. Patients on long-term hemodialysis will suffer from physical and mental stress as well as changes in lifestyle and personality. Fatique is an unpleasant subjective feeling in the form of complaints that are most often felt as many as $60-97 \%$ of the total patients undergoing HD, causing decreased concentration, malaise, sleep disturbances, emotional disturbances, and a decrease in the patient's ability to carry out daily activities so that it can reduce fatigue. quality of life of HD patients [4].

Although the hemodialysis therapy process takes 4-5 hours, generally it will cause physical stress to the patient after hemodialysis. Not to mention the problems that arise during the hemodialysis process, such as intradialytic hypotension, muscle cramps, headaches, nausea, hypertension, disequilibrium syndrome and so on. Patients will feel tired and sweat cold due to decreased blood pressure due to the effects of hemodialysis, one of which is anemia that often occurs in patients on hemodialysis due to reduced formation of erythropoietin in helping the formation of red blood cells. The presence of poor nutritional status can also cause sufferers to complain of malaise and fatigue. In addition, low oxygen levels due to anemia will cause the body to experience extreme fatigue (fatigue) and will force the heart to work harder to supply the oxygen it needs [5]. 
Hemodialysis Process Hemodialysis (HD) is one of the kidney replacement therapies that can be done, with an artificial kidney in the form of a dialyzer, HD serves as replacement therapy for loss of kidney function, HD patients generally experience a collection of symptoms of the uremic syndrome such as autonomic and motor neuropathy, myopathy in the heart muscle or skeletal, peripheral vascular changes (increased peripheral endurance, impaired oxygenation), anemia, dysfunction of bone metabolism, immunological hazards, and various physiological complaints (nausea, vomiting, insomnia, fatigue, depression, anxiety) This hemodialysis process can be performed 2-3 times a week and takes \pm 4-5 hours each time HD [6].

The patient's dependence on hemodialysis machines for life, role changes, job loss and income are stressors that can cause depression in hemodialysis patients with a prevalence of 15 - 69\%. Depression can affect the patient's physical appearance, causing fatigue, sleep disturbances and decreased interest in activities. Decreased physical activity in hemodialysis patients affects the level of fatigue. Most hemodialysis patients (75\%) only participate in household activities that are considered light. Decreased physical activity results in decreased muscle mass, muscle atrophy, weakness and fatigue [7].

The method of handling fatigue is carried out in two ways, namely pharmacological and non-pharmacological. Methods of adding L-carnitine, vitamin C and erythropoietin and treatment to control anemia. The last method developed is exercise, yoga, relaxation, acupressure, acupuncture, electrical stimulation, and dialysis [3].

The results of research conducted by [8] with the title: The effect of foot reflexology and back massage on hemodialysis patients' fatigue and sleep quality. The study included 105 patients who were enrolled in a private dialysis clinic and receiving hemodialysis treatment. Foot reflexology and back massage were given to the patient twice a week for 4 weeks. The difference between the pre test and post test mean scores of patients on the Scale for Fatigue and the Pittsburgh Sleep Quality Index was statistically significant $(p<0.001$ ) Leg reflexology and back massage were shown to improve sleep quality and reduce fatigue in hemodialysis patients.

One of the references in reducing fatigue symptoms and improving sleep quality in HD patients undergoing hemodialysis therapy is to do Foot Reflexilogy and back massage $2 x /$ week for 4-6 weeks. Therefore, this study aims to determine the effect of foot reflexology and back massage on the fatigue score in patients undergoing hemodialysis therapy at the Bekasi City General Hospital. 


\section{Methods}

\subsection{Design}

This type of research is quantitative research and the design of the forceps used is "Quasi Experimental Pre-Post test with Control Group" the treatment given is Foot Reflexology and Back Massage. The study was conducted to determine the changes in fatigue condition in patients undergoing hemodialysis before and after foot reflexology and back massage at the Bekasi City Hospital.

\subsection{Sample}

The sample was divided into two groups, namely the intervention group ( 24 people) and the control group (24 people).

\subsection{Procedure}

Sampling in this study used the technique of Non-Probability Sampling or Non-Random Sampling with the Purposive Sampling method, namely the technique of taking sample characteristics with certain considerations in accordance with what was desired by the researcher, as many as 48 respondents.

\subsection{Questionnaire for Data Collection}

Measurements were carried out twice, namely before treatment (pre test) and after treatment (post test). In the intervention group, respondents were given foot reflexology and structured back massage, while in the control group, respondents were given standard foot reflexology and back massage. Collecting data in this study using a questionnaire, namely the FAS Fatique Assamen Scale which has been tested for validity and reliability.

\subsection{Data Analysis}

Analisis data menggunakan ANOVA, t-Test Dependent. 
TABLE 1: Frequency distribution of hemodialysis respondents who experienced fatigue in hemodialysis respondents at the Bekasi City Hospital in $2017(n=24)$

\begin{tabular}{|c|c|c|c|c|}
\hline \multirow[t]{2}{*}{ Characteristics } & \multicolumn{4}{|c|}{ Group } \\
\hline & Intervention & $\%$ & Control & $\%$ \\
\hline $\begin{array}{l}\text { Gender } \\
\text { Female }\end{array}$ & 1410 & $\begin{array}{l}58,3 \\
41,7\end{array}$ & 1410 & 58.341 .7 \\
\hline $\begin{array}{l}\text { HD Duration }<3 \\
\text { Month } \geq 3 \text { Month }\end{array}$ & 024 & 0100 & 024 & 0100 \\
\hline $\begin{array}{l}\text { Kadar } \mathrm{Hb}<10 \\
\mathrm{mg} / \mathrm{dL} \geq 10 \mathrm{mg} / \mathrm{dL}\end{array}$ & 1410 & $\begin{array}{l}58.3 \\
41.7\end{array}$ & 177 & $\begin{array}{l}70.8 \\
29,2\end{array}$ \\
\hline
\end{tabular}

TABLE 2: Age equality analysis on hemodialysis respondents who experienced RLS and Sleep Quality symptoms in hemodialysis respondents at Bekasi City Hospital in 2017 ( $n=24)$

\begin{tabular}{|c|c|c|c|c|c|}
\hline Variable & Mean & Median & SD & Min-Max & $95 \% \mathrm{Cl}$ \\
\hline $\begin{array}{l}\text { Age Intervention Group } \\
\text { Control Group }\end{array}$ & $\begin{array}{l}55.46 \\
52.42\end{array}$ & $\begin{array}{l}55.00 \\
55.00\end{array}$ & $\begin{array}{l}3.934 \\
7.950\end{array}$ & $\begin{array}{l}46-6429- \\
62\end{array}$ & $\begin{array}{l}53.80-57.12 \\
49.06-55.77\end{array}$ \\
\hline
\end{tabular}

\section{Results}

\subsection{Univariate Analysis}

In this section, we will discuss the characteristics of hemodialysis patients who experience fatigue scores. Categorical variables in hemodialysis patients are age, gender, duration of $\mathrm{HD}$, and $\mathrm{Hb}$ levels which are presented in table 1 and table 2 as follows:

Based on table 2 above, the average age of respondents in the intervention group is 55.46 years with a standard deviation of 3,934. The youngest age is 46 years old while the oldest is 64 years old. From the results of the interval estimation, it can be concluded that at $95 \% \mathrm{Cl}$ it is believed that the average age of respondents in the intervention group is between 53.80 to 57.12 years. The average age of respondents in the control group was 52.42 years with a standard deviation of 7,950. The youngest age is 29 years old while the oldest is 62 years old. From the results of the interval estimation, it can be concluded that at $95 \% \mathrm{Cl}$ it is believed that the average age of respondents in the control group is between 49.06 to 55.77 years.

\subsection{Normality test}

Prior to the bivariate analysis, the normality test of the pre and post foot reflexology and back massage measurements was carried out with a fatique score. The normality test of the data was carried out using the Shapiro Wilk test because the number of samples was less than 50 people. This test aims to determine that changes in the average value 
TABLE 3: The results of the normality test for the value of the fatigue scale on the pre-test and post-test measurements in the intervention group and the control group on hemodialysis respondents at the Bekasi City Hospital in 2017 ( $n=48)$

\begin{tabular}{l|l|l} 
Variable & $\begin{array}{l}\text { Treatment } \\
\text { Pre scale Fatique }\end{array}$ & $\begin{array}{l}\text { Foot Reflexisologi } \\
\text { and Back Mas- } \\
\text { sage }\end{array}$ \\
\hline Intervention Group & 0,586 \\
\hline Control Group & 0,755 \\
\hline Post scale Fatique & & 0.177 \\
\hline Intervention Group & & 0,111 \\
\hline Control Group & &
\end{tabular}

TABLE 4: Analysis of Changes in Fatique Scale Values Before and After Treatment in the Intervention Group at the Bekasi City Hospital in 2017 (n 48)

\begin{tabular}{l|l|l|l|l} 
Variable & Mean & S.D & SE & P Value \\
$\begin{array}{l}\text { Scale Value Fatique } \\
\text { Before }\end{array}$ & & & 0,001 \\
\hline After & 26,83 & 4,361 & 0,890 & \\
\hline
\end{tabular}

of the fatigue score occur not because of the respondent's variation, but foot reflexology and back massage. If the $p$ value $>0.05$ then the data is homogeneous. The results of the normality test are illustrated in table 3 as follows:

Based on the results of testing the assumption of univariate normality in table 3 on the measurement of the fatigue score of the intervention group and pre-test control, the Shapiro Wiks test value is 0.586 , and 0.775 because the $P$ value $>0.05$ (greater than the alpha value), then $\mathrm{HO}$ is accepted, meaning the measurement variable baseline spread following a univariate normal distribution. While the post-intervention and control groups had the Shapiro Wiks test value of 0.177 , and 0.111 because the $P$ value $>0.05$ (greater than the alpha value), then $\mathrm{HO}$ was accepted, meaning that the baseline measurement variables spread following a univariate normal distribution.

\subsection{Bivariate Analysis}

In this study, data analysis was carried out using the dependent sample $\mathrm{t}$ - test (Paired t test) to see the difference before and after the variables, to see the difference between the intervention group and the control group using an independent $t$ test.

The analysis used by the researcher is a dependent $T$ test with the following results:

Based on table 6, it is known that the average change in the mean score of Fatique before the Foot Reflexiology and Back Massage was performed was 26.83 with a 
TABLE 5: Analysis of Changes in Fatique Scale Values Before and After Treatment in the Control Group at the Bekasi City Hospital in 2017 (n 48)

\begin{tabular}{l|l|l|l|l} 
Variable & Mean & S.D & SE & P Value \\
Scale Value Fatique & & & & 0,003 \\
\hline $\begin{array}{l}\text { Before } \\
\text { After }\end{array}$ & 31,83 & 4,018 & 0,820 & \\
& 11,42 & 1,036 & 0,208 &
\end{tabular}

standard deviation of 4.361. While the change in the average Fatique score after Foot Reflexiology and Back Massage was performed, the average value was 13.08 with a standard deviation of 1.100. It can be seen that there is a difference in the mean value of the Fatique scale before and after Foot Reflexiology and Back Massage are statistically tested. obtained $p$ value $>0.005$, it can be concluded that there is a significant difference between the Fatique score before and after the Foot Reflexiology and Back Massage exercises in the intervention group.

Based on table 7, it is known that the average change in the mean score of fatigue before Foot Reflexiology and Back Massage was performed in the control group was 31.83 with a standard deviation of 4.018 . Meanwhile, the average change in the fatigue scale after Foot Reflexiology and Back Massage is 11.42 with a standard deviation of 1.036. It can be seen that there is a difference between the value of the fatigue scale before and after the Foot Reflexiology and Back Massage in the control group. Statistical test results obtained a $\mathrm{p}$ value $>0.005$, so it can be concluded that there is a significant difference between the value of the Fatique scale before and after Foot Reflexiology and Back Massage in the control group.

\section{Discussion}

The hemodialysis process is an intervention that is carried out throughout the patient's life with the frequency of action every 2-3 times / week the duration of each hemodialysis takes 4-6 hours per hemodialysis session. As per the regulation, the minimum hemodialysis service is 10-12 hours per week [9].

Changes that will be caused in patients undergoing hemodialysis include clinical and psychological changes. Psychological changes that arise due to ESRD include physiological and psychological stress that can also contribute to sleep quality disorders. Clinical changes include fatigue, sexual dysfunction, decreased appetite, anemia, difficulty concentrating, skin disorders, and muscle pain (Restless Legs Syndrome) [10]. 
From several clinical problems Restless Legs Syndrome (RLS) is a problem that patients often complain about because it causes discomfort. Restless leg syndrome is a motor (movement) disorder characterized by an uncomfortable condition in the legs with symptoms such as aches and pains, a burning sensation, radiating nature, twitching of the legs, itching and tingling and cramps in the leg muscles. Patients who experience RLS problems will have an impact on Sleep Quality problems. Based on research conducted by Christoforos D. Giannaki, et all (2011) with the title "Evidence of Increased Muscle Atrophy and Impaired Quality of Life Parameters in Patients with Uremic Restless Legs Syndrome" in 70 CKD patients undergoing hemodialysis therapy including 30 dialysis patients. who had RLS symptoms and 40 dialysis patients who did not have RLS.

In overcoming the symptoms of restless leg syndrome and sleep quality disorders, there are several studies to overcome them, including stretching exercises, this has been proven by [5] with the title "Stretching Exercise on Severity of Restless Legs Syndrome in Patients on Hemodialysis" in 33 patients. Those who underwent hemodialysis therapy at Hasherminejad Hospital in Tehran consisted of the intervention group ( $n=17)$ and the control group ( $n=16)$. Giving stretching exercises to the patient's legs in the first hour of dialysis 3x/week for 8 weeks in the intervention group, the results showed that RLS symptoms were reduced after being given stretching exercises $3 x /$ week for 8 weeks with a $P$ value $<0.001$ compared to the incidence of RLS in the control group.

This study also showed that intradialytic stretching exercise performed during hemodialysis in the intervention group could significantly reduce RLS symptoms and improve sleep quality. The average RLS symptoms decreased and increased sleep quality significantly from 1.74 to 0.42 ( $p$ value $=0.000$ ). This is reinforced by a study conducted by Mansooreh Aliasgharpour, et all (2016) with the title "Stretching Exercise on Severity of Restless Legs Syndrome in Patients on Hemodialysis" in 33 patients undergoing hemodialysis therapy at Hasherminejad Hospital in Tehran including the intervention group ( $n=17$ ) and control group $(n=16)$. Giving stretching exercises to the patient's legs in the first hour of dialysis 3x/week for 8 weeks in the intervention group, the results showed that RLS symptoms were reduced after being given stretching exercises $3 x /$ week for 8 weeks with a $P$ value $<0.001$ compared to the incidence of RLS in the control group.

After doing intradialytic stretching exercise in the intervention group, the average RLS symptoms decreased and increased sleep quality significantly from 1.74 to 0.42 ( $p$ value $=0.000$ ), this result was different from the control group which only had an average of 
1.68 to $1.47(p$ value $=0.104)$. These results indicate that there are differences in RLS symptoms and sleep quality disorders between the intervention group and the control group. The results of this study strengthen the evidence that intradialytic stretching exercise performed in the intervention group showed a decrease in RLS symptoms and increased sleep quality. The results of this study are in accordance with research conducted by [11] entitled "The Effect in Intradialytic Stretching Exercise on Severity of Symptoms of RLS and Quality of Sleep in Hemodialysis Patient" in 37 patients undergoing hemodialysis at Hasheminejad Hospital in Tehran, including: there is a control group ( $n=16)$ and an intervention group $(n=17)$. The results showed that at the end of week 8, data obtained that stretching exercise performed in the intervention group could significantly reduce RLS symptoms and improve sleep quality compared to the control group with $\mathrm{P}$ value $<0.001$ and $\mathrm{P}$ value 0.003 .

Based on the results of previous studies that became a reference for researchers, it can be concluded that RLS symptoms in dialysis patients will generally occur in patients undergoing hemodialysis and these symptoms will be experienced more often when patients want to start resting, namely at night. Symptoms of RLS experienced by dialysis patients will interfere with the patient's rest and sleep because the perceived symptoms such as tingling, cramps, itching, burning in the patient's legs will worsen the patient's sleep both in quantity and quality. In this case, dialysis patients who experience RLS symptoms and it is known that there is a decrease in sleep quality are given an intradialytic stretching exercise intervention in accordance with established standard procedures, which will reduce the perceived RLS symptoms. This happens because the exercise will increase relaxation in the muscle mass of patients who experience atrophy due to CKD disease experienced by patients. Increased relaxation in the muscle mass can relieve symptoms of discomfort in the legs so that the patient's sleep quality can be improved by giving the exercise intervention.

\section{References}

[1] Lee YJ, Shin SJ, Wangc RH, Lind KD, Lee YL, Wang YH. Pathways of empowerment perceptions, health literacy, self-efficacy, and self-care behaviors to glycemic control in patients with type 2 diabetes mellitus. Patient Education and Counseling - Journals. 2016;99:287-294.

[2] Malisa N, Ibrahim K. Manajemen diriuntuk mengatasi fatigue pada pasien hemodialisis: Kajian literatur sistematis. Jurnal Kesehatan Bakti Tunas Husada Jurnal IImu-ilmu Keperawatan, Anal Kesehatan dan Farmasi. 2016;16:101-112. 
[3] Eglence R, Karatas N, Tasci S. The effect of acupressure on the level of fatigue in hemodialysis patients. Alternative Therapies In Health And Medicine. 19.

[4] Jhamb M, Pike F, Ramer S, et al. Impact of fatigue on outcomes in the hemodialysis (HEMO) study. American Journal of Nephrology. 2011;33:515-523.

[5] Aliasgharpour M, Abbasi Z, Razi SP, et al. The effect of stretching exercises on severity of restless legs syndrome in patients on hemodialysis. Asian Journal of Sports Medicine. 7.

[6] LeMone P, Burke KM, Luxford Y, et al. Medical-surgical nursing: Critical thinking in client care. Australia: Pearson; 2011.

[7] Septiwi C. Pengaruh breathing exercise terhadap level fatigue pasien hemodialisis di RSPAD gatot subroto Jakarta. Jurnal IImu Kesehatan Keperawatan. 9.

[8] Unal KS, Akpinar RB. The effect of foot reflexology and back massage on hemodialysis patients' fatigue and sleep quality. Complementary Therapies in Clinical Practice. 2016;24:139-144.

[9] Hulin L, Timby J, Muftah AM, et al. Western marmarica coastal survey 2010: Preliminary report. Libyan Stud. 2010;41:155-162.

[10] Himmelfarb J, Sayegh MH. Chronic kidney disease, dialysis, and transplantation ebook: A companion to Brenner and Rector's The Kidney. Elsevier Health Sciences; 2010.

[11] Soltani NS, Abbasi DZ, Mahmoudi M. The effect of quality of life training on selfefficacy in patients under hemodialysis treatment. 